\title{
Study Research Coordinator
}

National Cancer Institute

\section{Source}

National Cancer Institute. Study Research Coordinator. NCI Thesaurus. Code C153124.

A person who handles the administrative responsibilities of a study on behalf of the study investigator, acts as a liaison between study site and study sponsor, and reviews all data and records before a monitor's visit. 